\title{
VAREJO VIRTUAL DE DEPARTAMENTO: suas barreiras e sucessos
}

\author{
V irtual department retail: their barriers and successes
}

\begin{abstract}
Thais Martins Lopes
Mestranda em Comunicação Social. E specializada (UME SP), Universidade Metodista de São Paulo. São Bernardo do Campo, SP - Brasil, e-mail: thaislop@ gmail.com
\end{abstract}

\section{Resumo}

Na atualidade possuímos grandes nomes de empresas que exercem a função de varejo virtual de departamento, ou seja, lojas que vendem uma ampla variedade de produtos e marcas na Internet. Nossa meta é discutir os problemas enfrentados pelos gigantes do universo online e o que impediu uma maior expansão desse mercado. Mesmo com a teórica positividade desse meio, além de ter conquistado uma boa porcentagem de seu público estimado e crescido espantosamente nos últimos anos, o segmento de vendas virtuais encontra algumas barreiras. $G$ rande parte da população ainda considera a venda virtual perigosa. Por meio de pesquisa bibliográfica, documental e de campo, este trabalho avalia a situação varejista e reflete sobre essa incógnita que impede maior expansão do varejo virtual, especialmente o de departamento. Chega-se à conclusão de que esse mercado apresenta possibilidades de crescimento, desde que haja investimento na educação do consumidor e na mudança de atitude diante a este novo cenário.

Palavras-chave: Varejo virtual; E-consumidor, Segurança.

\begin{abstract}
Today we have some names of big companies engaged in the function of the virtual department retail, or stores that sell a wide variety of products and brands on the Internet. Our objective is discussing the problems faced by the giants of the online universe and what prevented a further expansion of this market. Even with the theoretical positivity that environment, besides it had won a good percentage of its audience estimated and grown amazingly in recent years, the segment of online sales get some barriers. Much of the population considers the virtual sale dangerous. Through literature, documentary and field search, this study assesses the retailer situation and reflects on the question that prevents a further expansion of virtual retailers, especially of the department. It reaches the conclusion that this market presents opportunities for growth, provided there is investment in education of consumers and in the change of attitude forward to this new scenario.
\end{abstract}

Keywords: Virtual retail; E-consumer; Security. 


\section{INTRODUÇÃO}

Frente ao cenário de grande expansão da Internet e abertura de novos canais em seu universo, surge o comércio eletrônico, uma forma inovadora das empresas se comunicarem entre si e com seus consumidores. Paralelo a esse fato destaca-se 0 amplo enfoque comercial no sistema varejista, que apesar de se revelar a grande força do mercado atual, tenta suprir as exigências do público e sua crescente busca por distinções entre as marcas do mesmo setor. Com isso, o varejo uniu-seao comércio eletrônico, lançando as "lojas virtuais", uma nova opção de compras ao público moderno. Apesar da inovação e da teórica positividade desse meio, 0 segmento de vendas virtuais encontra algumas barreiras. Boa parte da população ainda não está apta a enquadrar-se na definição de "econsumidores". A intenção desse trabalho é desvendar a incógnita que impede maior expansão do varejo virtual, especialmente o de departamento.

\section{O COMÉRCIO NA INTERNET}

A Internet tornou-se um grande mercado em curto prazo. Atualmente existem várias empresas presentes nesse meio, seja apenas como mais um canal de venda ou como serviço único, cada dia mais as companhias desco brem o universo virtual e suas vantagens.

Apesar desse crescimento, muitas pessoas ainda confundem-se quanto ao conceito de venda cibernética e todos os seus vieses, tais como comércio eletrônico, canais de venda online, varejo e lojas virtuais, entre outros.

Para a grande maioria, tudo o que é vendido pela Internet trata-se da mesma coisa, mas não é bem assim. Apesar de muitos autores considerarem o mundo comercial eletrônico um aglomerado geral, algumas características evidenciam suas diferenças, segmentando cada assunto específico em sua própria classificação.

Devemos separar os conceitos de cada um. Não cabe, por exemplo, colocarmos "canais de vendas" no mesmo setor que "lojas virtuais". Enquanto o primeiro é apenas mais uma opção criada pelo lojista em comercializar seus produtos, a segunda éuma forma específica de venda, mesmo que a companhia possua também lojas físicas.
O u seja, as lojas virtuais são sites específicos para o comércio, podendo possuir ou não lojas concretas no mundo real, já os canais de venda, são apenas links posicionados na página institucional do lojista, direcionados à comercialização de alguns de seus produtos ou serviços.

O comércio eletrônico, ou ecommerce, é caracterizado pela venda virtual, seja qual for sua classificação. Neste contexto, podemos matematicamente dizer que 0 varejo virtual está contido em ecommerœ, mas jamais o oposto. $\mathrm{Na}$ realidade, canais de venda, lojas virtuais, etc, são segmentos mercadológicos do comércio eletrônico.

\section{O VAREJO VIRTUAL DE DEPARTAMENTO}

Não tem como falar sobre comércio na Internet ou qualquer avanço que ela tenha proporcionado sem ao menos citar a G lobalização. Esse sistema mercadológico globalizado leva para um mercado mais competitivo, fazendo com que surjam novas empresas, novas formas de se comercializar produtos e, o que mais afeta no mercado mundial, nasça o conglomerado de grandes empresas, as quais passam a dominar diversos ramos em vários países.

Tendo em vista o conceito de Globalização, é fácil relacioná-la ao varejo virtual, já que a Internet proporciona venda de um país para o outro, ou seja, graças a esse avanço, uma pessoa do Brasil pode importar produtos do Japão com apenas um dic.

Resumidamente, podemos caracterizar o varejo como um intermediário, que liga a empresa ao consumidor final. Nosso grande foco está no varejo não lojista, que compreende a venda pela Internet, juntamente com o de departamento, que engloba a venda de vários itens e diversas marcas.

A cima de se atualizar ao mercado, esse setor procura se atualizar ao consumidor, o qual se torna cada vez mais exigente e ocupado. No mundo de hoje, não éapenas por luxo e praticidade que as pessoas tendem a comprar pela Internet, mas também, pela correria diária de sua rotina. Tudo isso leva o varejista moderno a correr para o mundo cibernético como mais uma opção de negócio e ampliação em seu sistema comercial.

"Os mercados de massa serão coisas do passado. Em seu lugar haverá um número grande 
de pequenas áreas de mercado, atendendo a consumidores que queiram atingir um grau mais elevado de realização e satisfação" Wahlström (apud FRANÇA; SIQUEIRA 1997, p. 232).

Um ponto positivo para o varejo eletrônico é 0 alcance. As lojas virtuais podem ser acessadas a qualquerhorário eem qualquer lugar, diferentemente das lojas concretas. Com isso, o crescimento desse setor não aconteceu apenas no meio urbano, atingiu também as cidades interioranas do país. Segundo pesquisas da E-bit, empresa de pesquisas de vendas virtuais, o faturamento no interior das regiões Sul, Sudeste e Centro-O este exerceram um aumento significativo nos primeiros três meses de 2005, além das cidades localizadas no Norte e Nordeste do Brasil, as quais, nessa mesma época, cresceram $1 \%$ comparado ao ano anterior.

O varejo virtual de departamento é composto por lojas onde se encontra uma grande diversidade de produtos e marcas, mas que ao em vez de serem físicas, funcionam pela Internet.

Hoje em dia, graças à recente junção das duas maiores lojas do ramo, Submarino e Americanas, o grupo B2G - Companhia Global do Varejo, é quem lidera o ranking do setor de departamento virtual.

O Submarino foi criado especialmente para atuar no ramo cibernético, já a Americanas.com, foi fundada para auxiliar nas vendas e lucros da companhia Americanas.

Apesar de muitos confundirem as Lojas Americanas com a Americanas.com, e ambas fazerem parte da mesma corporação, elas se diferem entre si, e não é apenas pelo fato de uma trabalhar no meio eletrônico e a outra no físico. As funções, produtos, ofertas, e até mesmo valores não são os mesmos. Cadauma possui um grupo defuncionários distintos, e certas mercadorias podem muitas vezes ser encontradas em somente uma delas.

O nome "Americanas" foi mantido pela credibilidade no mercado quea empresajá possuía no ramo de varejo, mas a funcionalidade é totalmente outra.

O utro grande nome do varejo virtual atual é o Pontofrio.com. 0 nome da empresa, segundo 0 próprio Ponto Frio (2007, online), é a tradução de uma geladeira norte-americana da época, carrochefe das vendas da nova loja carioca, a qual se chamava Coldspot. A inda deacordo com a empresa, o site foi lançado em 1996, mas nessa época, não funcionava como loja virtual especificamente, e sim, como uma espécie de catálogo eletrônico, onde os produtos eram apresentados para o público, além de informações sobre a companhia. A ideia de utilizar o site como mais um canal de venda surgiu no ano posterior para auxiliar a recuperação de crescimento, que foi comprometido por suas concorrentes diretas, Marabraz e Casas Bahia. Seu problemafoiresolvido eaospoucos os consumidores foram percebendo as vantagens, as quais as outras empresas do ramo não ofereciam.

\section{Caso Mercado Livre: um intermediário à parte}

Q uando falamos em venda pela Internet, e, principalmente, quando é mencionado o significado de "varejo virtual de departamento", ou seja, lojas eletrônicas, que comercializam uma imensa variedade de produtos e marcas distintas, logo se vêm em mente o gigante atual do comércio na Internet: o Mercado Livre. Mas será que esse serviço pode ser considerado varejo virtual?

Para chegar a essa conclusão é necessário primeiramente estabelecer alguns conceitos e características desse grande canal de vendas.

O Mercado Livre é um site onde podemos encontrar uma ampla diversidade de produtos, e até mesmo serviços de muitas categorias distintas. É considerado o maior site de ecommerce da A mérica Latina.

Porém, o varejo é um estabelecimento que comercializa mercadorias "compradas" de fornecedores, para assim, revendê-las ao público final. O Mercado Livre não compra os produtos oferecidos em seu espaço. Ele apenas cobra uma taxa do anunciante para que a venda seja concretizada em seu site. Seria uma espécie de "feira online". De certa forma possui algumas características em comum com o varejo, uma delas é 0 fato de também se tratar de um intermediário, ligando o fornecedor com o consumidor. A diferença é que o varejo paga esse fornecedor para comercializar os produtos; já o Mercado Livre, cobra dos vendedores para que esses possam anunciar. Apesar disso, essa forma de "leilão eletrônico" concorre com os varejistas virtuais, pois "comercializa" os mesmos tipos de produtos e oferece preços geralmente inferiores.

O grande problema dosleilões eletrônicos éa segurança, comprometendo os demais mercados da Internet. A pesar das qualificações e dos vários 
meios de compra oferecidos, esse comércio não oferece garantia nenhuma.

Sabendo diferenciar varejo virtual de departamento com leilões eletrônicos, podemos partir para o nosso próximo item, compreender 0 público internauta, e assim, o consumo ou não consumo do comércio online.

\section{O E-CONSUMIDOR}

Com a tecnologia avançando todos os dias, novos canais de venda se abrindo e o mercado expandindo cada vez mais para meios alternativos, como a Internet, por exemplo, o consumidor do século XXI torna-se constantemente mais exigente, procurando por vantagens e facilidade, e isso é o que o leva para as compras virtuais.

A pesquisa realizada (pela autora) entre os meses de Junho à Agosto de 2007 com universitários do Grande ABC, no estado de São Paulo, e trabalhadores da empresa Zema Zselics LTD A, também situada nessa região, que totalizou o número de 80 entrevistados, $62,5 \%$ consumidores e 37,5\% não consumidores, apontou a facilidade como maior vantagem do comércio eletrônico.

D o total deconsumidores, $97 \%$ declararam a facilidade como uma das maiores qualidades desse mercado; 48,5\% acham positivo o valor oferecido nas vendas virtuais; 34\% destacaram a importância das várias formas de pagamento; e $20 \%$ sugeriram outras qualidades desse comércio.

Podemos concluir ainda que os homens possuem maior hábito de compra que as mulheres.

O utro número revelado pela eCConsumers ${ }^{\circledR}$, exposta no Ilanet (2007, online), envolvendo cerca de 4.000 entrevistados latinoamericanos, é em relação aos compradores que se autoafirmam heavy users desse mercado, ou seja, aqueles que adquirem produtos pela Internet com uma grande frequência, atingindo a casa dos $40 \%$.

Um dos possíveis motivos para o hábito de compra seja o tipo de conexão utilizada. Segundo nossa pesquisa, enquanto $91,5 \%$ dos consumidores possuem Banda Larga, apenas $73 \%$ dos não consumidores possuem esse tipo de conexão. Parece não ser grandea diferençade números, masébastante significativa para o hábito de uso da Internet, e consequentemente, compra por esse meio.

Os consumidores do universo digital também possuem a característica de passar mais tempo navegando do que os não consumidores. $80 \%$ dos consumidores virtuais acessam a Internet todos os dias, enquanto apenas 19,5\% dos não consumidores passam todo esse tempo online.

Uma questão que devemos ter em mente é que nem todos os mercados estão aptos a adequarem-se totalmente a esse meio, ou melhor, nem todos os consumidores de diferentes mercados estão dispostos a se adequarem a esse padrão.

Existem algumas vantagens disponíveis apenas fora do mundo virtual, uma delas é 0 contato físico e palpável com o produto.

Muitas categorias não exigem esse contato mais íntimo do consumidor, porém, existem os produtos que requerem maiores cuidados eatenção, como por exemplo, os alimentícios. Será que o público aceitaria comprar uma fruta sem um contato prévio ou sem saber suas reais condições?

Apesar disso, muitas pessoas preferem 0 supermercado digital, pois limita suas compras exatamente àquilo que está imposto em sua lista, coisa que não acontece quando visita um supermercado real.

Sendo assim, cada empresa deveconhecer suas necessidades e flexibilidades, além de saber 0 limite de aceitação de seu determinado público.

Existem aqueles que se distraem fazendo compras nos supermercados, que gostam de passear pelos corredores e conhecer as novidades, como existem aqueles que não possuem esse tipo de hábito, ou não têm tempo na correria diária para isso, encontrando no universo digital a escapatória de seus problemas. Basta a empresa conhecer seu público e saber onde exatamente ele se encaixa.

\section{Direitos do e-consumidor}

G randeparte da confusão no varejo virtual se deve ao fato de não haver especificamente um item no Código de D efesa do Consumidor ligado ao ramo do comércio eletrônico. Com isso, as regulamentações impostas nos demais mercados devem ser adaptadas a esse segmento.

Nada difere na compra de itens em lojas habituais com as de serviço online. 0 que complica um pouco mais a situação do público internauta é o fato do código ser cabível apenas em território nacional. O u seja, quando o fornecedornão possui filiais ou representantes no Brasil, o requerimento pela lei é mais complexo. 
Seporum lado essainexistência de barreira geográfica é um ponto positivo no comércio virtual, nesse caso, encontramos diversos pontos negativos.

Uma dica é o consumidor, antes da transação, confirir se o site do fornecedor existe, assim como seus contatos físicos e dados cadastrais da empresa, como o CNPJ, por exemplo, através do endereço www.registro.br.

O Ministério da Justiça (2007, online) recomenda ao público guardar todos os documentos e mensagens utilizados na transação entre ele e 0 fornecedo. Essesarquivos servem como comprovantes da compra caso necessário sua utilização.

Para resolver os conflitos no meio digital também foi criado o IBCI - Instituto Brasileiro de Proteção e D efesa dos Consumidores da Internet, 0 qual, segundo Lima (2007, online), é uma entidade não governamental que objetiva defender os direitos do e-consumidor, além de melhorar a relação das partes envolvidas na compra virtual, evitando a demora excessiva no processo do Poder Judiciário.

Mas não é apenas a lei que protege e auxilia o público internauta a prevenir-se de problemas no varejo virtual. Existem muitos guardiões desses consumidores localizados na própria rede, facilitando a decisão do público em relação a que loja eletrônica comprar.

Há dois tipos de sites que prestam esse tipo de serviço. Porum lado existem aqueles queapontam ao público as lojas virtuais que dispõem da mercadoria desejada, assim como o valor em cada umadelas, como o caso do ShoppingUOL, BuscaPé, Bondfaro, entre outros; e por outro lado, existem aqueles os quais o público pode expor sua opinião sobre as lojas eletrônicas e sua experiência de compra, sendo possível avaliá-las em todos os aspectos, além de conferir a nota e comentários de outras avaliações descritas nos sites. Esse é o caso novamente do BuscaPé, assim como do "Nunca mais.net".

D esse modo, o consumidor pode se sentir mais seguro o optar por determinada loja. Quando desejar algum produto e decidir utilizar a rede como comércio, basta entrar em um desses sites antes de realizar a compra e localizar a mercadoria desejada. Além de se prevenir de possíveis complicações associadas à Internet, o comprador ainda facilitará o processo de pesquisa por valores e ofertas, o qual, em um estabelecimento físico, deveria ser feito pessoalmente, levando-0 a dirigir-se em todas as possíveis lojas e fazer por si mesmo as comparações.

\section{BARREIRAS DO CONSUMO VIRTUAL E ASFORMAS DE COMBATE}

Existem vários fatores que levam às barreiras da compra virtual.

Para osconsumidores, deacordo com nossa pesquisa, os maiores problemas da aquisição pela Internet são: 57\% a segurança; 25\% a entrega; 20\% 0 atendimento; $57 \%$ o serviço de troca; $3 \%$ outros, como por exemplo, a descrição do produto pode não corresponder à realidade; e 5,5\% não comentaram.

A pesar da segurança e do pós-venda ter o mesmo número de votos, quando falamos em prioridade, ou seja, a maior razão que bloqueia esse consumo, 48,5\% do total dizem ser a segurança, enquanto 25,5\% alegam ser a troca.

Em relação à nossa análise sobre os não consumidores, quando falamos em credibilidade, 84,5\% alegam não conheceras medidas desegurança obrigatoriamenteadotadas pelos sites devenda online. Esse dado explica porque o público não adepto às compras virtuais desconfiam desse tipo de vendas, já que essas empresas possuem várias formas de garantir a segurança de seus clientes.

Apesar das más experiências passadas e do preconceito formado namentedosconsumidores em comprar pela Internet, hoje em dia existem diversos softwares e programas que impedem o roubo de identidades, além de formas de seguranças a serem adotadas pelos usuários, especialmente compradores daInternet. Uma delas éa criptografia.

Um dos serviços de criptografia mais utilizados é o do cadeado na barra do servidor. Se 0 cadeado estiver fechado, significa que 0 site é seguro, porém se estiver aberto, significa que 0 usuário deve suspeitar da página.

Esse cadeado é uma maneira de proteção emitido por certas empresas de certificação virtual. O utra ferramenta desenvolvida por essas empresas é o "semáforo eletrônico". O funcionamento desse serviço é simples. A cor verde é atribuída para sites seguros e vermelho para páginas falsas ou de riscos a segurança.

Uma das primeiras medidas a ser tomada ao acessar a Internet é a instalação de antivírus e firewalls, que impedem a invasão de fraudadores, vírus, cavalos de troia, warms, entre outros males presentes no meio digital.

As senhas também são importantes. 0 mais indicado é a utilização de letras e números, dificultando o descobrimento dos códigos. Outra 
dica é não adotar palavras conhecidas, sequer existentes no dicionário, contendo de seis a oito caracteres. Trepper (2000, p. 220) cita dois tipos de senha, umaboa "\%R*m9", euma ruim "totó". O utro fator que facilita a descoberta da senha é associá-la a nomes, características, lembranças e preferências pessoais, como hobbies, artista ou cor favorita, nome da mãe, do pai, da primeira professora, etc.

Também é fundamental a criação de várias senhas, sendo atribuídas para cada local.

Não é recomendado ter os dados e senhas salvas no computador ou em cookies, pois caso um intruso invada a máquina, pode obter facilmente as informações contidas.

O s e mails também estão repletos de males que acabam comprometendo a credibilidades de muitas empresas, principalmente as que trabalham através da Internet. São os chamados "scams" ou, em português, golpes.

São mensagens falsas que utilizam o logo ou assinatura de determinadas empresas no intuito de fraudar documentos e dinheiro das vítimas, ou apenas infestar a máquina de quem acessa o link de vírus.

As companhias alertam ao usuário não acessar 0 endereço passado por e-mail, principalmente quando não fizeram compra alguma na loja. Em caso de dúvida, o consumidor deve acessar 0 site da empresa ou entrar em contato no telefonedeatendimento ao cliente. Mas vale ressaltar que o link não deve ser acessado. 0 público deve digitar o endereço conhecido da empresa, e caso não conheça, procurá-la em algum site de busca.

O bviamente as companhias do segmento online reconhecem os problemas de segurança atribuídos à Internet, e, como atuantes desse mercado devem se atualizar em um sistema mais seguro, e assim, informar seus consumidores sobre os métodos adotados.

A Americanas.com eo Submarino possuem um link intitulado "Segurança" em suas páginas, onde se comprometem com seus consumidores a manter os dados obtidos em suas redes protegidos e explicam os métodos de garantia das vendas.

O certificado obtido por ambas é emitido pela Verisign, uma das maiores empresas que garantem a segurança na Internet.

Em relação aos falsos emails enviados com o nome das companhias, as empresas dão as dicas para identificá-los.

De acordo com o canal E-mails falsos ou SPAM (2007, online), o endereço eletrônico da
Americanas.com, disponível, contendo mensagens promocionais é apenas 0 "email@americanas.com.br"; além disso, as promoções enviadas estão também no site da empresa, e seus emails nunca contêm arquivos anexos.

O Submarino também explica em E-mails do Submarino (2007, online) que todos os e-mails da empresa são enviados pelo endereço "direto@mkt.submarino.com.br" e apenas para os seus clientes, diante a prévia aprovação dos mesmos e as promoções de emissores diferentes a esse são falsas.

Outro aparente problema nesse mercado seria o serviço de atendimento ao cliente, principalmente no setor de troca de mercadorias. 0 fato de não existir um contato físico e direto entre consumidor e vendedor atrapalha a comunicação e confunde o público.

Em uma loja física as pessoas se dirigem ao funcionário mais próximo e resolvem seu problema. Esse processo étotalmente diferenteno ramo virtual.

Q uando algum item comprado vem errado ou com defeito, muitos consumidores cometem 0 mesmo erro indo até uma loja da companhia que possua o mesmo nome da loja virtual, como por exemplo, Lojas A mericanas e Americanas.com, para tentar a troca, e se deparam com a mesma resposta, a que as empresas, real e virtual, são da mesma organização, porém, de setores diferentes, não sendo realizada a troca.

Para auxiliar o consumidor nesse ou em outros problemas as lojas virtuais dispõem em suas páginas virtuais dúvidas e respostas mais frequentes, além de um documento contendo a Política de Troca das empresas. Nesse espaço o público pode também fazer outras perguntas, que em um prazo de 24 horas devem ser respondidas por um dos atendentes da empresa.

Apesar de haver um local específico para esse atendimento, assim como um endereço para suas reclamações, nem todos os consumidores encontram esses locais. O usuário deve navegar pelo site para encontrar a solução de seus problemas, não havendo funcionários para auxiliá-lo em caso de dúvida ou localizá-lo quando necessário.

Outra desvantagem é a simultaneidade. Ao contrário da conversa por meio do contato físico, a comunicação pelo computador é mais lenta. Não existe um sincronismo de perguntas e respostas. 0 usuário deve primeiramente encontrar 0 atendimento ao consumidor na página eletrônica, 
para em seguida fazer sua pergunta e aguardar um atendente respondê-la. Se a dúvida não for esclarecida, ou se surgirem outras dúvidas, o usuário deverá repetir o procedimento. Isso faz com que um problema rápido se prolongue, podendo chegar á dias até seu esclarecimento.

A troca também é mais demorada nesse sistema. Enquanto na loja concreta basta 0 consumidor se dirigir até o estabelecimento e trocar seu produto, na virtual ele deve fazer 0 requerimento de troca, para que assim, quando seu pedido for aceito, enviar o produto ao local determinado, e por fim, aguardar o retorno, que pode demorar até um mês, já que as lojas virtuais não trabalham com estoque.

Embora existam muitos problemasligados ao setor de atendimento ao cliente no varejo virtual, todas as lojas possuem em suas páginas suas formas de contato por telefone, endereço e e-mail.

\section{METODOLOGIA}

Para o início desse trabalho foi necessário o estabelecimento do método exploratório, onde podemos destacar a pesquisa bibliográfica, uma busca completa em livros, e documental, que estuda matérias e documentos expostos na Internet. Em seguida foi utilizado o método descritivo para analisar os dados obtidos nas pesquisas anteriores.

Por fim foi adotada a pesquisa de campo, com os consumidores e não consumidores do meio online, no intuito de obter uma conclusão concreta sobre a opinião desses dois públicos em relação à compra no varejo virtual.

\section{PRIN CIPAIS RE SULTADOS}

Com base em nossa pesquisa podemos constatar que um dos grandes bloqueadores da expansão varejista virtual seja a má experiência que boa parte da população internauta possua com 0 atendimento não físico, seja pelo computador, através de emails, ou pelo telefone, com os serviços de telemark eting. Porém, o maior vilão ainda é o leilão eletrônico, que apesar de diversas semelhanças com o varejo, não utiliza as regras básicas de segurança, confundindo o e-consumidor a respeito da credibilidade do comércio eletrônico.
Apesar desses obstáculos, o mercado virtual tem crescido bastante nos últimos anos, e tende a crescer ainda mais.

D e acordo com nossa pesquisa, 74\% estão satisfeitos com a compra pela Internet; 14\% estão moderadamente satisfeitos; $8,5 \%$ estão muitos satisfeitos e apenas 3\% não estão satisfeitos.

Sendo assim, podemos dizer que o varejo virtual vem atendendo as expectativas de seu público, já que grande parte apresenta um bom grau de satisfação.

\section{CON SIDERAÇÕES FINAIS}

Através de nosso estudo podemos observar os principais obstáculos e qualidades da venda virtual, especialmente relacionada ao setor varejista de departamento. Com a realização da pesquisa foi possível estimar que a maioria das pessoas aindanão conheça as formas de segurança utilizadas pelo comércio eletrônico. Além disso, muitas confundem a denominação e características de uma loja do segmento de varejo virtual de departamento com as de leilões eletrônicos, interferindo na credibilidade do público em relação a tudo que é vendido pela Internet.

Se essas pessoas fossem mais bem informadas sobre as formas de certificações dos sites, talvez confiassem mais nesse meio inovador de compra.

Além disso, alguns consumidores não estão adaptados à comunicação não-visual, preferindo se deslocarem até as lojas físicas, onde têm a certeza que serão atendidos e suas dúvidas sobre o produto resolvidas.

Contudo, a compra virtual tende a facilitar a vida de todos, uma vez que pode ser adquirida de qualquer lugar e a qualquer horário, por valores relativamente menores que no mercado concreto.

\section{REFERÊNCIAS}

AMERICANAS.com. D isponível em: <http:/ / a t e n d i m e n t o.b 2 wi n c . c o m? action $=$ get\&element $=$ Answer centro\&qid $=236890 \&$ match number $=9 \&$ q cat $=\overline{2} 00143 \&$ th $=$ acom $>$. Acesso em: 08 mar. 2007. 
AMERICANAS.com. E-mails falsos ou SPAM. D isponível em: <http:// atendimento.b2winc.com ?action $=$ get $\&$ element= Answer centro\&qid $=236891 \& \mathrm{match}$ number $=7$ \&qcat=200143\&th $=$ acom\&question $=\bar{E}$ ail + falso + ou + SPA M \& categ $=200142>$. Acesso em: 08 mar. 2007.

E-Bit: Disponível em: <http:/ / www.ebit.com.br/ sala imprensa/ html/ 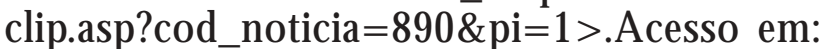 09 fev. 2007.

FRANCA， Sandra Helena Abrahão; SIQUEIRA, João Paulo Lara de. Comércio Virtual: Tecnologia para o segmento varejista. In: ANGELO, Claudio Felisioni; SILVEIRA, José Augusto Giesbrecht. Varejo competitivo. São Paulo: Atlas, 1997, v. 2.

ILANET. Disponível em: <http:/ / www.ilanet.com.br/ cgi-local/ portal/ bin/ view/ Persona/ Comportamento>. Acesso em: 14 mar. 2007.

LIMA, Rogério Montai. Regulamentação nas relações de consumo via Internet. 2007. Disponível em: <http:// www.ambitojuridico.com.br/ site/ index.php?n link=revista artigos leitura\&artigo id=279>. Acesso em: $\overline{1} 2$ abr. $\overline{2} 007$.
MINISTÉRIO da Justica: Disponível em: <http:/ / www.mj.gov.br/ dpdc/ internet.htm>. Acesso em: 22 jun. 2007.

PONTO Frio. Disponível em: <http:/ / carrinho.pontofrio.com.br/ Hotsite/ Conhecao-Ponto-Frio.aspx?Id=16 >. A cesso em: 08 mar. 2007;

SUBMARINO. Disponível em: Segurança: <http:/ / atendimento.b2winc.com/ ?action $=$ get\&element=Answer centro \& $\mathrm{id}=237058 \& \mathrm{match}$ number $=1 \& \mathrm{cat}=$ $200171 \&$ th $=$ sub\&question $=$ Seguran $\%$ E 7a $>$ Acesso em: 08 mar. 2007.

. Disponível em: E-mails do Submarino: $\overline{\langle} \overline{\mathrm{t}} \overline{\mathrm{t}} \mathrm{p}: / /$ atendimento.b2winc.com/ ?action $=$ get\&element $=$ Answer centro $\&$ id $=237062 \& \mathrm{match}$ num $\bar{b}$ er $=2 \&$ cat $=200171 \&$ th $=$ sub $\&$ question $=\mathrm{E}-$ mails+do+Submarino>. A cesso em: 08 mar. 2007.

TREPPER, Charles. Estratégias de ecommerce. Rio de Janeiro: Campus, 2000.

Recebido: 29/ 05/ 2008 Received: 05/ 29/2008

Aprovado: $23 / 09 / 2008$ A pproved: $09 / 23 / 2008$ 